\title{
The metabolism of isoforms of human adiponectin: studies in human subjects and in experimental animals
}

\author{
Philip W Peake, Adamandia D Kriketos ${ }^{1}$, Lesley V Campbell ${ }^{1}$, Yvonne Shen and John A Charlesworth \\ Division of Medicine, Prince of Wales Hospital, Randwick, New South Wales 2031, Australia and ${ }^{1}$ Garvan Institute of Medical Research, St Vincents \\ Hospital, Darlinghurst, New South Wales 2010, Australia
}

(Correspondence should be addressed to P Peake; Email: P.Peake@unsw.edu.au)

\begin{abstract}
Objective: Little is known of the metabolism of different isoforms of adiponectin. We therefore (a) characterised the size distribution of human adiponectin in relation to gender, body composition and following a challenge with a fat meal or oral glucose in humans, and (b) studied the metabolism of isoforms of human adiponectin in rabbits.

Method: Electrophoresis, blotting and chromatography were used to characterise human adiponectin in 36 healthy subjects, including 15 with at least two first-degree relatives with type 2 diabetes, before and after consumption of a fatty meal or glucose. The metabolism of column-fractionated human adiponectin was studied in rabbits, some of which were coinjected with insulin.

Results: Females had a higher proportion of high molecular weight (HMW) and hexameric adiponectin $(P=0.002$ and 0.004 respectively $)$, and a lower proportion of trimers $(P<0.0001)$ than males. Females also showed a strong negative relationship between body fat measures and the proportion of HMW adiponectin. There were no differences in isoforms between insulin-resistant and -sensitive subjects, or following oral glucose or a fat meal. Adiponectin in rabbits had an extravascular/intravascular ratio of 0.71 , and a half-life $(\mathrm{T} 1 / 2)$ of $14.3 \mathrm{~h}$. Metabolism was not influenced by insulin or reduction of sulphydryl bonds. HMW and trimeric isoforms had a significantly different T1/2 of 13.0 and $17.5 \mathrm{~h}$ respectively $(P<0.05)$, and these isoforms did not interconvert in vivo.

Conclusions: Human adiponectin is present as trimers, hexamers and HMW forms. Females had a higher proportion and absolute amount of HMW species compared with males, and female, but not male, subjects showed a strong negative relationship between measures of body fat, and the proportion of HMW species. These isoforms did not respond to challenge in man with a fatty meal or oral glucose, and in the rabbit, to injected insulin. HMW adiponectin was more rapidly metabolised than the trimeric form, but both were stable in vivo, and did not interconvert. We conclude that human adiponectin is much longer-lived than is the case with other hormones, a finding with positive implications for the potential to supplement levels of adiponectin in man.
\end{abstract}

European Journal of Endocrinology 153 409-417

\section{Introduction}

Adiponectin is an adipose-specific protein that circulates at high concentration in the plasma and is believed to enhance insulin sensitivity, and suppress hepatic glucose production (1). Insulin sensitising drugs such as thiazolidinediones significantly increase plasma adiponectin in both humans and rodents (2). Circulating levels also correlate negatively with the presence of cardiovascular disease in patients with type 2 diabetes (3), consistent with the hypothesis that this protein also acts as a protective factor for the cardiovascular system (4). Paradoxically, since the protein is produced only by fat tissue, levels of adiponectin also correlate negatively with adiposity (5).
Studies in mice also suggest that adiponectin plays a role in insulin resistance and fat metabolism. Adiponectin knockout mice have delayed clearance of plasma fatty acids (6), and may exhibit a moderate to severe degree of insulin resistance $(6,7)$. Supplementation of adiponectin in vivo leads to a reduction in serum glucose in the absence of increased insulin secretion (1). Furthermore, treatment of mice with a globular fragment of adiponectin significantly decreases the elevated levels of plasma free fatty acids caused by administration of a high fat test meal (8), while supplementation in vivo ameliorated atherosclerosis in apolipoprotein E-deficient mice $(9,10)$.

In man, adiponectin assembles into higher order structures (11), as do the related molecules C1q and 
the mouse homologue Acrp30. However, the nature and function(s) of these isoforms have not been fully characterised, and their response to physiological stimuli remains unclear. In mice, levels of the high molecular weight (HMW) complex are significantly reduced in response to insulin or glucose gavage (12), while in man mutant forms of the molecule with impaired ability to multimerise have been linked to diabetes (13). However, in some assays monomers or a globular fragment are more biologically active than higher order structures $(8,12)$.

Because different isoforms of Acrp30 induce different physiological responses $(12,13)$, characterisation of the behaviour in vivo of these isoforms should aid interpretation of the established correlations between total levels of adiponectin and phenomena such as insulin resistance and cardiovascular protection $(4,14)$. It would also provide important information necessary before therapeutic supplementation of adiponectin in man is attempted. In this study we established a sensitive assay capable of characterising different isoforms of adiponectin in native human plasma and related these to gender and body composition. Two groups of subjects were investigated: (i) a clinically healthy control group with no family history of diabetes, and (ii) a similarly healthy group with significantly reduced insulin sensitivity. This latter group consisted of normoglycaemic subjects with at least two first-degree relatives with type 2 diabetes ('relatives'). We then related variations in levels of multimers between groups and genders to body composition. We also examined whether oral glucose or a fat meal had any acute effects on isoform distribution.

Because of the favourable effects in mice of administration of adiponectin on fatty acid transport and vascular physiology, we then examined the metabolic behaviour of the native molecule and its high and low molecular weight isoforms in rabbits. The fractional catabolic rate and extravascular/intravascular distributions were calculated from plasma disappearance curves, and the generation of different isoforms was examined in relation to administration of i.v. insulin.

\section{Materials and methods}

\section{Subjects}

Thirty-six healthy, sedentary, non-smoking subjects (22 females/14 males) were included. They comprised a clinically healthy control group with no family history of diabetes, and relatives. There were no significant differences between females and males, or between the controls and relatives in terms of body mass index (BMI) or amount of central fat $(\mathrm{kg})$ (Table 1). The St. Vincent's Hospital Human Research Ethics Committee approved the study and all subjects gave written informed consent.

The protocols used to characterise the subjects and administer a fat meal and an oral glucose tolerance test have been reported previously in a study on a similar group of subjects $(15,16)$. Body composition was assessed by dual energy emission x-ray absorptiometry (DEXA) and whole-body insulin sensitivity by a 120min euglycaemic, hyperinsulinaemic clamp. Subjects received an oral fat meal, containing approximately $80 \mathrm{~g}$ dietary fat with an energy content of $4250 \mathrm{~kJ}$, while fifteen females from the normal population were given glucose $(1 \mathrm{mg} / \mathrm{g})$ orally over $5 \mathrm{~min}$.

\section{Blood analyses}

Plasma glucose was determined using a YSI glucose analyser (YSI 2300 StatPlus; YSI, Yellow Springs OH, USA). Inter- and intra-assay coefficients of variation were $<10 \%$.

Adiponectin levels in samples from human subjects were measured by a commercial RIA (Linco, St Charles, MO, USA).

\section{Electrophoretic analysis of adiponectin}

To take advantage of its superior resolution, serum proteins were analysed by native electrophoresis in 5\% acrylamide gels containing trisglycine buffer, $\mathrm{pH} 8.3$, and $1 \mathrm{mM} \mathrm{Ca}^{++}$, followed by Western blotting. Blots were probed with a monoclonal antibody to adiponectin (BD Biosciences, Sydney, Australia), which was detected with an affinity purified, alkaline phosphatase-conjugated antibody to mouse immunoglobin (Sigma, Sydney, Australia). These were scanned and analysed by Kodak Digital Science (New Haven CT) $1 \mathrm{D}$ image analysis software. Intra- and interassay coefficients of variation were $\leq 11 \%$ and $16 \%$ respectively. The absolute amount of adiponectin in each isoform was determined by multiplying the fraction present by the overall concentration of adiponectin.

\section{Animal metabolic studies}

Adult female New Zealand rabbits $(2.5-3.5 \mathrm{~kg}$ in weight) were used in all experiments. To minimise protein denaturation, experiments were performed with serum from a single adult volunteer in good health, not on medication, with a BMI of $29 \mathrm{~kg} / \mathrm{m}^{2}$.

\section{Experimental protocol}

The experimental protocol included the following groups: (1) five rabbits received 2 to $2.5 \mathrm{ml}$ serum only; (2) five rabbits received 2 to $2.5 \mathrm{ml}$ serum containing $2 \mathrm{U} / \mathrm{kg}$ Actrapid insulin; (3) six rabbits received up to $8 \mathrm{ml}$ of a preparation of serum containing predominantly high molecular weight (HMW) isoforms of adiponectin; (4) six rabbits received up to $8 \mathrm{ml}$ of a preparation of serum containing predominantly low molecular weight (LMW) isoforms of adiponectin; (5) two rabbits received a preparation of serum in which adiponectin had been fully reduced by incubation with dithiothreitol (DTT). 
Table 1 Subject characteristics. Data are expressed as mean \pm S.E.M.

\begin{tabular}{lccccc}
\hline & All subjects $(n=36)$ & Controls $(n=21)$ & Relatives $(n=15)$ & Male $(n=14)$ & Female $(n=22)$ \\
\hline BMI $\left(\mathrm{kg} / \mathrm{m}^{2}\right)$ & $24.8 \pm 0.8$ & $23.8 \pm 0.9$ & $26.1 \pm 1.4$ & $26.2 \pm 1.0$ & $23.8 \pm 1.1$ \\
Adiponectin $(\mu \mathrm{g} / \mathrm{ml})$ & $18.8 \pm 1.5$ & $19.3 \pm 1.9$ & $17.9 \pm 2.5$ & $11.3 \pm 1.5$ & $23.5 \pm 1.5 \dagger$ \\
GIR $(\mu \mathrm{mole} / \mathrm{min} / \mathrm{kg}$ FFM) & $60.1 \pm 3.1$ & $66.0 \pm 4.1$ & $52.0 \pm 3.9^{\star}$ & $65.0 \pm 5.7$ & $57.0 \pm 3.5$ \\
Central abdominal fat $(\mathrm{kg})$ & $1.23 \pm 0.11$ & $1.11 \pm 0.14$ & $1.41 \pm 0.19$ & $1.27 \pm 0.19$ & $1.21 \pm 0.15$ \\
Central abdominal fat $(\%)$ & $26.7 \pm 1.7$ & $24.8 \pm 2.2$ & $29.3 \pm 2.5$ & $23.3 \pm 2.5$ & $28.8 \pm 2.1$ \\
Fat $(\%)$ & $29.4 \pm 1.8$ & $27.1 \pm 2.2$ & $33.2 \pm 2.7$ & $23.1 \pm 2.4$ & $33.8 \pm 2.0 \ddagger$ \\
\hline
\end{tabular}

${ }^{*} P=0.02, \dagger P=<0.001, \ddagger P=0.002$ for differences between controls and relatives, or males and females, as determined by unpaired $t$-test.

$\mathrm{GIR}$, glucose infusion rate.

Serum was injected into a marginal ear vein. Blood samples in ethylene diaminotetraacetic acid were drawn from the contralateral ear at $10 \mathrm{~min}$, and for up to $51 \mathrm{~h}$ post injection: i.e. until $<8 \%$ remained in the plasma compartment. The University of New South Wales (UNSW) Animal Research Ethics Committee gave consent to these investigations.

\section{Purification of adiponectin and its isoforms}

Before injection, all samples of serum were equilibrated with sterile nonpyrogenic saline by passage through a G25 column. Fractions containing predominantly high or low molecular weight adiponectin were prepared by passage at $4{ }^{\circ} \mathrm{C}$ of serum down a $2.5 \times 90 \mathrm{~cm}$ column of Sephacryl S300 equilibrated with phosphate-buffered saline in pyrogen-free water.

\section{Reduction of adiponectin}

Serum was incubated with $0.1 \mathrm{M}$ DTT for $60 \mathrm{~min}$ at $37^{\circ} \mathrm{C}$.

\section{Analysis of adiponectin}

Adiponectin levels in samples from FPLC analyses and from rabbits injected with human adiponectin (see below) were measured by a sensitive monoclonal sandwich ELISA specific for human adiponectin (R\&D Minneapolis, MN, USA). Interference in this assay by rabbit adiponectin was $<1 \%$. The concentration of the related molecule $\mathrm{Clq}$ was determined by a sandwich ELISA standardised against donor serum diluted in rabbit serum. Wells were coated with rabbit anti C1q (Dako Glostrup, Denmark), and bound $\mathrm{C} 1 \mathrm{q}$ was detected with goat anti-human $\mathrm{Clq}$ (Cappel Irvine, CA, USA) diluted in 5\% rabbit serum, followed by an alkaline phosphatase-conjugated monoclonal antibody to goat IgG (Sigma).

\section{Sulphydryl group detection}

Sulphydryl groups were detected with Iodoacetyl-LCBiotin (Pierce Rockford, IL, USA) following the manufacturer's instructions.

\section{Superose column chromatography}

Adiponectin in plasma was resolved by chromatography on an FPLC Superose 12 column (Pharmacia) equilibrated with $0.05 \mathrm{M}$ Tris buffer.

\section{Statistical analysis}

Comparisons between groups were performed using oneway ANOVA with Dunnett and Bonferroni post tests, and paired and unpaired $t$-tests. Relationships between continuous variables were assessed by two-tailed Pearson correlation analyses. Allowance was made for the potentially confounding effect on significance of multiple comparisons by reducing the threshold for acceptance according to the formula $1-0.95^{1 / n}$, where $\mathrm{n}$ is the number of hypotheses being tested. The amount of human adiponectin present in rabbit serum was plotted against time after injection, with the assumption that levels at $10 \mathrm{~min}$ represented $97 \%$ of the injected dose. The analysis of data was carried out by Matthews' exponential analysis, by fitting of data to a two-phase exponential decay equation (GraphPad Prism San Diego, CA, USA), essentially as previously described (17). Results are presented as means \pm S.E.M.

\section{Results}

\section{Subject characteristics}

The age of the subjects was between 25 and 45 years with BMIs $<35 \mathrm{~kg} / \mathrm{m}^{2}$ (Table 1). Control subjects had $27 \%$ higher insulin sensitivity than first degree relatives of patients with type 2 diabetes, but did not differ significantly in BMI or body fat composition (Table 1).

\section{Adiponectin isoforms}

Adiponectin in normal serum ranged in size from $\sim 1000 \mathrm{kDa}$ to species of $\sim 200 \mathrm{kDa}$ (Fig. 1a). The latter contained essentially all of the detectable free sulphydryl groups within adiponectin (Fig. 1a), and the distribution of reduced adiponectin was essentially identical. However, on removal of DTT, adiponectin was able to reassociate to a near normal distribution. 


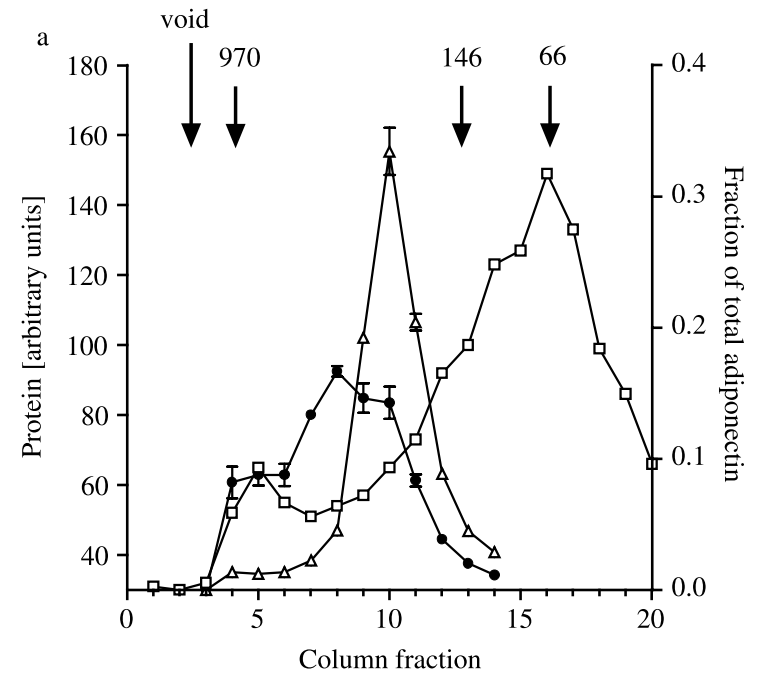

$\mathrm{b}$

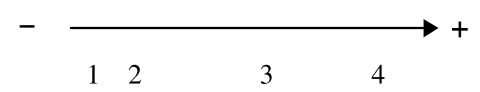

A

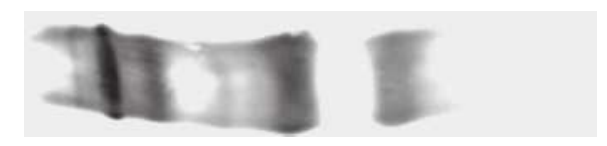

$\underline{\text { Native }}$

B

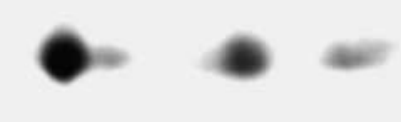

$\underline{\text { SDS-Page }}$

Figure 1 (a) The elution profile of plasma protein on a size-sorting Superose $12 \mathrm{gel}(\square)$. The positions of IgM (970 kDa), IgG $(146 \mathrm{kDa})$, and albumin $(66 \mathrm{kDa})$ are shown by arrows. Also shown is the elution profile of human adiponectin detected by ELISA $(\bullet)$ and of adiponectin isoforms containing free sulphydryl groups $(\Delta)$. Data are shown as means \pm S.E.M. (b) Western blot of adiponectin in plasma analysed in the first dimension by native electrophoresis (gel A). Bands in this gel were further resolved by reducing SDS-PAGE electrophoresis in the second dimension (gel B). Four bands were clearly resolved in both dimensions. The direction of electrophoresis (negative to positive) is shown by arrows.

Native gel electrophoresis provided improved resolution over FPLC of adiponectin isoforms, and resolved 4 different bands (Fig. 1b). FPLC analysis confirmed that electrophoretic separation was based on size, and the largest bands (HMW, 1 and 2) moved the least into the gel. Band 4 was identified as trimeric adiponectin based upon its size and the fact that when reduced by DTT all serum adiponectin was present in band 4 . All four bands were confirmed to contain adiponectin by two-dimensional electrophoresis into reducing SDS-PAGE gels (Fig. 1b).

\section{Correlation with subject characteristics}

Following the approach of Pajvani et al. (18), adiponectin levels in the two HMW bands ( 1 and 2) were pooled as HMW adiponectin; levels of these varied together and showed similar correlations with body characteristics and gender. We confirmed the well-known sex differential in adiponectin levels between males and females (Table 1), and showed that females had a significantly higher proportion of HMW and hexameric adiponectin compared with males $(0.32 \pm 0.01$ vs $0.26 \pm 0.01$, $P=0.002$ and $0.39 \pm 0.01$ vs $0.33 \pm 0.02, P=0.004$ respectively), but a significantly lower proportion of trimeric adiponectin $(0.28 \pm 0.01$ vs $0.41 \pm 0.02$, $P<0.0001)$. When absolute amounts of adiponectin were compared, levels of all isoforms were significantly greater in females than in males (HMW: 7.6 \pm 0.61 vs $3.0 \pm 0.5, \quad P<0.0001$; hexamer: $9.2 \pm 0.6$ vs $3.8 \pm 0.61, P<0.0001$; trimer: $6.6 \pm 0.5$ vs $4.6 \pm 0.6$, $P=0.01)$.

When all subjects were considered, the proportion of HMW adiponectin was negatively correlated with BMI $(\mathrm{r}=-0.38, P \leq 0.02)$, and with central abdominal fat $(\mathrm{kg})(\mathrm{r}=-0.34, P<0.05)$. Female, but not male, subjects showed a strong negative relationship between measures of body fat and the proportion of HMW isomers. Correlations between central abdominal fat $(\mathrm{kg})$, central abdominal fat (\%), and fat (\%) for this group were $-0.48,-0.49$ and -0.52 respectively; $P \leq 0.02$ for each. Although the controls and relatives differed significantly in insulin sensitivity, there were no significant differences between these groups in terms of the concentration of serum adiponectin or the amount of adiponectin of any particular size. This was also true when males and females from each group were considered individually. There was also no relationship between insulin sensitivity in all subjects (range 24.3-111.4 $\mu \mathrm{mole} / \mathrm{min} / \mathrm{kg}$ fat-free mass (FFM)) and levels of adiponectin in total, or of the proportion of adiponectin in each isoform.

\section{Postprandial response to a high fat meal}

Postprandial values of triglyceride, insulin, non-esterified fatty acid and triglyceride were similar in the relatives of patients with diabetes and control subjects, and to those in similar studies using the same fat meal (15, 16). Glucose levels were essentially unchanged, and there was no significant difference $(<5 \%)$ between the proportions of each adiponectin isomer present in basal and postprandial samples.

\section{Response to an oral glucose tolerance test}

In 15 female subjects from the normal population, mean levels of adiponectin did not change significantly, and the proportions of adiponectin present in each 
isoform were unchanged $(<6 \%)$ following an oral glucose tolerance test.

\section{In vivo behaviour of adiponectin}

Human adiponectin injected into rabbits showed an initial rapid fall in level, followed by a log-linear phase of slower decline (Fig. 2a). Reducing sodium dodecyl sulphate (SDS) analysis followed by Western blotting confirmed that the protein was circulating intact, with essentially no breakdown products. Analysis of the decay curve showed adiponectin has a mean fractional catabolic rate (FCR) of $8.7 \% / \mathrm{h}$, an extravascular: intravascular (ev/iv) ratio of 0.71 , and a half-life (T1/2) of $\sim 14 \mathrm{~h}$ (Table 2 ). These characteristics were unaffected by the coinjection of insulin (Fig. 2a), although
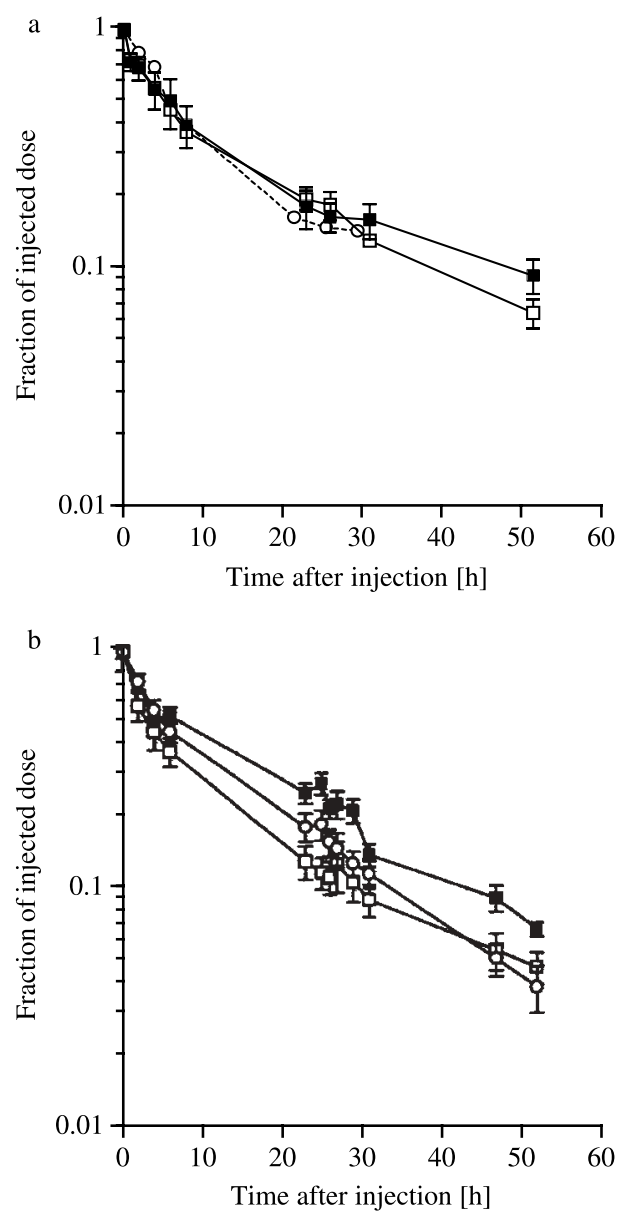

Figure 2 (a) Adiponectin disappearance curves for control rabbits (घ) and those coinjected with $2 \mathrm{U} / \mathrm{kg}$ Actrapid insulin ( $\square$ ). The plasma disappearance curve for serum pretreated with DTT to reduce sulphydryl bonds is also shown (--- $\bigcirc---)$. Data are shown as means \pm S.E.M. or, for DTT, the mean of 2 rabbits. (b) Adiponectin disappearance curves in rabbits for serum fractionated to isolate low ( $\square$ ) and high ( $\square$ ) molecular weight isoforms. The disappearance curve of $\mathrm{C} 1 \mathrm{q}(0)$ in rabbits injected with the high molecular weight isoforms is also shown. Data are shown as means \pm S.E.M. levels of glucose declined from $6.6 \pm 0.2$ to $3.8 \pm 0.6$ $1 \mathrm{~h}$ post injection, recovering to $4.7 \pm 0.4 \mathrm{mmol} / \mathrm{l}$ at $2 \mathrm{~h}$.

\section{Treatment with DTT}

Following DTT treatment, the metabolic behaviour of reduced adiponectin was similar to that seen with normal serum (Fig. 2a), while the size distribution of the isoforms was similar to that seen in normal serum (see below).

\section{In vivo behaviour of high and low molecular weight forms of adiponectin}

Data from experiments on serum preparations enriched in HMW and LMW forms of adiponectin showed that the former had a significantly higher FCR and a shorter T1/2. However, the ev/iv ratios did not differ significantly (Fig. 2b, Table 2). The metabolic characteristics of the related molecule, Clq, were not significantly different to that of HMW adiponectin (Fig. 2b, Table 2).

\section{Size distribution of adiponectin in vivo}

By $2 \mathrm{~h}$ post injection in both control rabbits and those injected with insulin, the proportion of high molecular weight isoforms had significantly declined (fractions 4 and 5), while the proportion present as the trimer had significantly increased (fractions 10 and 12) (Fig. 3). However, there were no significant effects resulting from injection with insulin.

The semipurified LMW fraction predominantly consisted of trimers, and the relative distribution of this fraction did not change significantly for up to $31 \mathrm{~h}$ in vivo (Fig. 4a). Only 22\% of the injected dose of the HMW preparation was present in fractions 9-13 at 10 min post injection, but this rose significantly so that at $31 \mathrm{~h}$ post injection, $37 \%$ of adiponectin was present in these fractions (Fig. 4b). However, allowance must be made for the lower fractional catabolic rate of low molecular weight adiponectin. The actual concentration of adiponectin present in fractions $9-13$ is $3.0 \%$ of the injected dose, while the amount that would be predicted from consideration of the decay characteristics of the low molecular weight isoforms present at $10 \mathrm{~min}$ post injection is 3.9\% (Table 2).

\section{Discussion}

In man, the physiochemical nature of adiponectin has not been fully characterised, and its response to physiological stimuli remains unclear. We showed that human adiponectin is present in size ranges that correspond to the trimers, hexamers and HMW forms described in mice (19), including two forms of HMW complexes not separable by conventional chromatography. The identification of the isoform with an apparent 
Table 2 Metabolic parameters for human adiponectin, its high (HMW) and low (LMW) molecular weight isoforms, and for C1q.

\begin{tabular}{lccr}
\hline & Fractional rate $(\% / \mathrm{h})$ & Catabolic ev/iv & T1/2 $(\mathrm{h})$ \\
\hline Adiponectin control $(n=5)$ & $8.7 \pm 1.4$ & $0.71 \pm 0.23$ & $14.3 \pm 1.2$ \\
Adiponectin $+2 \mathrm{U} / \mathrm{kg}$ insulin $(n=5)$ & $7.9 \pm 0.04$ & $0.64 \pm 0.06$ & $17.0 \pm 1.1$ \\
LMW adiponectin $(n=6)$ & $6.6 \pm 0.5^{*}$ & $0.65 \pm 0.07$ & $17.5 \pm 1.1^{*}$ \\
HMW adiponectin $(n=6)$ & $12.0 \pm 2.1^{*}$ & $1.08 \pm 0.38$ & $13.0 \pm 0.9^{*}$ \\
C1q $(n=6)$ & $8.7 \pm 2.2$ & $0.65 \pm 0.18$ & $14.4 \pm 1.7$ \\
\hline
\end{tabular}

${ }^{*} P<0.05$ for differences between HMW and LMW adiponectin.

molecular mass, under gel filtration, of $200 \mathrm{kDa}$ as a trimer is consistent with published models of the mouse homologue, in which an elongated trimer contains a disulphide bond, and one accessible sulphydryl group. Reduction of sulphydryl groups collapsed all isoforms into trimers in mice (20) and in our studies of human subjects. Since we found no accessible sulphydryl groups in isoforms other than the trimer, these are most likely non-covalent associates of the disulphide-linked hexamer, rather than a mixture of hexamers and trimers.

Adiponectin isoforms appear stable in vivo in man, as the proportions and amount of each did not change after the ingestion of either a fatty meal or glucose. Similarly, when the metabolism of human adiponectin was studied in rabbits, the administration of insulin did not significantly affect its half-life or multimeric distribution. As well, adiponectin was relatively long-lived in comparison with other hormones, with an average half-life in the rabbit of approximately $14 \mathrm{~h}$. This figure may be underestimated, as human proteins typically exhibit more rapid metabolism in the rabbit than in man. Thus $\mathrm{C} 3$, the third component of human complement, has a $\mathrm{T} 1 / 2$ in the rabbit of approximately $37 \mathrm{~h}$,

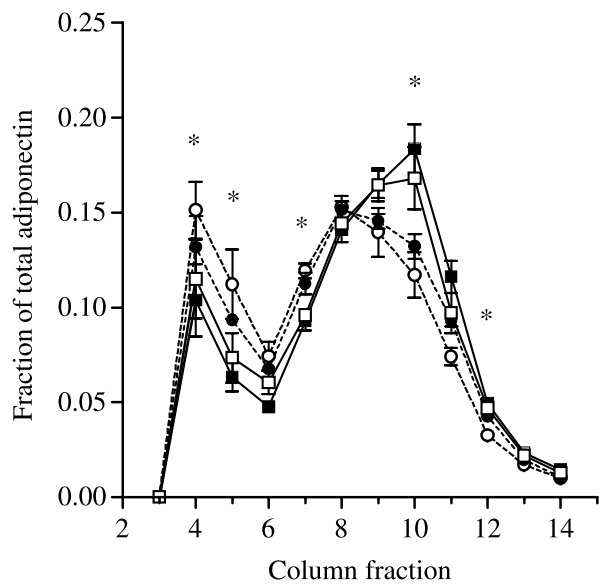

Figure 3 An FPLC analysis of the size distribution of human adiponectin following injection of serum into rabbits. Data are shown at $10 \mathrm{~min}(\bullet)$ and $2 \mathrm{~h} \mathrm{(} \boldsymbol{( \bullet )}$ post injection for control rabbits, and at $10 \mathrm{~min}(\circ)$ and $2 \mathrm{~h} \mathrm{( \square )} \mathrm{post} \mathrm{injection} \mathrm{for} \mathrm{those} \mathrm{treated} \mathrm{with} \mathrm{Actrapid}$ insulin. Data are shown as means \pm S.E.M., and significant differences $(P<0.05)$ between the amount of adiponectin in each fraction are shown $(*)$. but $70 \mathrm{~h}$ in man (21). In comparison, rabbit $\mathrm{C} 3$ has a $\mathrm{T} 1 / 2$ of $29 \mathrm{~h}$ when reinjected into rabbits (21). The comparability of our data on the behaviour of the adiponectin-related molecule $\mathrm{Clq}$ in the rabbit to published turnover data on $\mathrm{Clq}$ in man $(22,23)$ supports our conclusions on the metabolic behaviour of adiponectin. These findings have positive implications for the potential to supplement levels of adiponectin in man, a procedure suggested because of
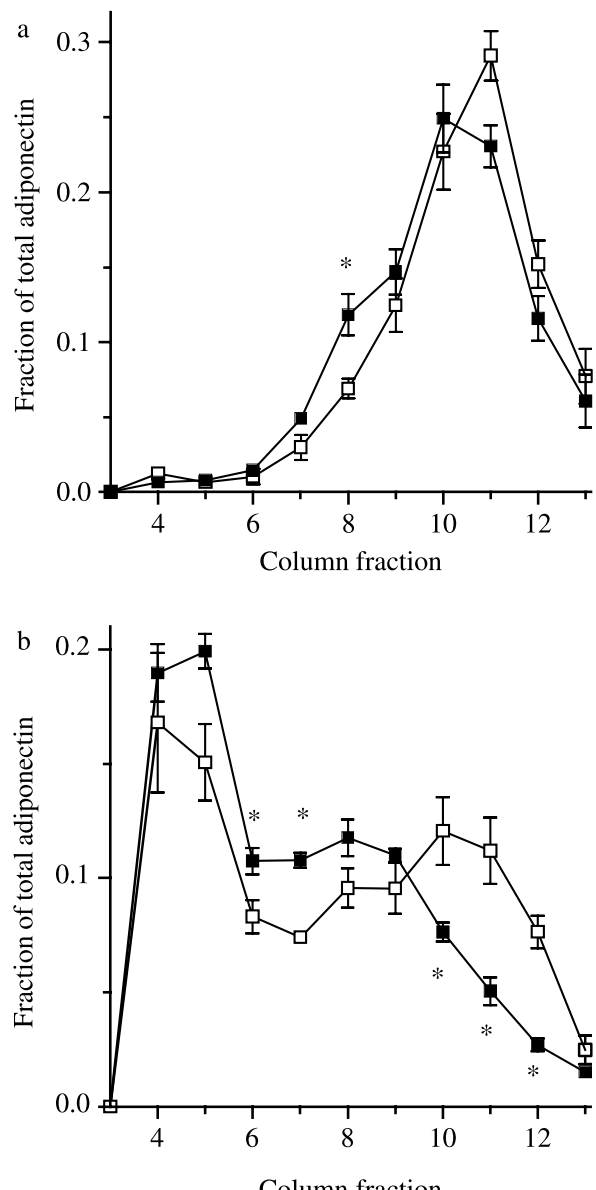

Column fraction

Figure 4 An FPLC analysis at $10 \mathrm{~min}(\square)$ and $31 \mathrm{~h} \mathrm{( \square )} \mathrm{post} \mathrm{injec-}$ tion of the size distribution of human adiponectin following injection of serum fractionated into low (a) and high (b) molecular weight isoforms into rabbits. Data are shown as means \pm S.E.M., and significant differences between the amount of adiponectin in each fraction are shown $\left({ }^{*}\right)$. 
experimental demonstrations of its ability to protect against vascular disease and to increase insulin sensitivity $(1,9,10)$. As well, the mean ev/iv ratio of 0.71 indicates that approximately $42 \%$ of the total pool resides in the extravascular compartment, so that the rapid and significant changes in circulating levels reported in some studies (e.g. a fourfold increase in postprandial adiponectin within $60 \mathrm{~min}$ (24)) may reflect compartmental redistribution.

Individual isoforms of adiponectin induce different physiological responses $(12,13)$. Similarly, they displayed different metabolic characteristics; HMW forms had a mean $\mathrm{T} 1 / 2$ of $13.0 \mathrm{~h}$ that was significantly shorter than that of $17.5 \mathrm{~h}$ found for LMW. Nevertheless, these were stable in vivo under a variety of conditions despite the fact that in vitro adiponectin, reduced to the trimer, reassembled into a range of isoforms with similar size characteristics and metabolic behaviour to the native molecule. These findings differ from those in the mouse, where it has been proposed that reduction of the disulphide bond in the Acrp30 homologue is an important step in its activation to a short-lived trimeric form (12). The quantity and stability of the trimers detected in this study suggest this is not the case in man. In addition, HMW isoforms in mice had a longer $\mathrm{T} 1 / 2$ (9 h) than hexamers $(4.5 \mathrm{~h})$, but the recombinant preparation studied had been precipitated, then radiolabelled, by extended oxidation with chloramine T. There was minimal in vitro manipulation of the preparations in our study, and the high Y-axis intercepts of the final exponentials of the plasma disappearance curves confirmed there was little denatured or rapidly cleared material present.

Although primarily concerned with metabolic behaviour, our data also show sexual dimorphism of adiponectin isoforms, with females having a significantly higher proportion of HMW and hexamers, and a significantly lower proportion of trimers. Females had significantly higher amounts of all isoforms, reflecting their higher absolute levels of adiponectin, as do female mice (12). It is possible these differences are related to the well-known differential between male and female in terms of fat distribution and metabolism (25), and the selective inhibition of the secretion of HMW adiponectin by testosterone (26)

Total adiponectin concentrations are negatively correlated with BMI (27), and our data suggest this depended largely upon the proportion of HMW adiponectin. In females, there were significant negative correlations between the proportion of HMW isomers and measures of body fat; correlations were not observed with the proportions of hexamers or trimers. Total adiponectin levels have been associated with insulin sensitivity $(14,27)$, and improved insulin sensitivity following thiazolidinedione treatment correlated with an increase in the proportion of HMW isomers (18), possibly resulting from a direct effect of thiazolidinedione on their synthesis; it was not seen in subjects treated with metformin (18). While significantly more insulin resistant than the control group, the relatives in this study did not differ in total adiponectin (28), or in the proportion of HMW isomers. However, a study of subjects with type II diabetes and a greater reduction in insulin sensitivity might be more powerful in detecting such a relationship.

Most studies of adiponectin in man have not shown short-term responses to a variety of stimuli, and these could be difficult to effect, given its high concentration and long half-life. Instead, its concentration appears to change only over a prolonged period of time, in response to changes in such parameters as body weight, hormone levels, and insulin sensitivity. The role of the various multimeric forms of adiponectin remains to be determined. Although receptors for both a globular fragment and full-length adiponectin have been described, the quantities we detected for each multimeric form would be sufficient to signal via the receptor for the full-length molecule, since the $K_{\mathrm{d}}$ for AdipoR2 is $\sim 0.8 \mu \mathrm{g} / \mathrm{ml}$ (29). This could suggest some property of the molecule other than just its multimeric status initiates receptor signalling in vivo, despite considerable data showing distinct physiological responses induced by different multimeric forms (12, 13). The role of posttranslational modifications such as glycosylation on the activity of the molecule remains to be fully elucidated $(30,31)$, as do variations in receptor number and type. Alternatively, it has recently been found that the various oligomeric complexes of adiponectin bind selectively to different growth factors, thus controlling their bioavailability and inflammatory potential at a pre-receptor level (32), and obviating the need for receptor interaction to induce a physiological response. These findings differ from those in mice, where it has been reported that levels of the HMW complex were significantly reduced in response to a systemic increase of insulin (12). Differences between mice and man in the metabolic roles of adiponectin isoforms may derive from differences such as those in the $\mathrm{N}$ terminal sequence, which is important in the formation of oligomers (13).

In summary, we showed that human adiponectin is present as trimers, hexamers and HMW forms. Females had a higher proportion and absolute amount of HMW species compared with males, and female, but not male, subjects showed a strong negative relationship between measures of body fat, and the proportion of HMW species. These isoforms did not respond to challenge in man with a fatty meal or oral glucose, and in the rabbit to injected insulin. HMW adiponectin was more rapidly metabolised than the trimeric form, but both were stable in vivo, and did not interconvert. With a mean $\mathrm{T} 1 / 2$ of $14.3 \mathrm{~h}$, human adiponectin is much longer lived than is the case with other hormones, a finding with positive implications for the potential to supplement levels of adiponectin in man. 


\section{Acknowledgements}

We gratefully acknowledge the technical assistance of Melissa Sam in this study.

\section{References}

1 Berg AH, Combs TP, Du X, Brownlee M \& Scherer PE. The adipocyte secreted protein Acrp30 enhances hepatic insulin action. Nature Medicine 20017 947-953.

2 Maeda N, Takahashi M, Funahashi T, Kihara S, Nishizawa H, Kishida K, Nagaretani H, Matsuda M, Komuro R, Ouchi N, Kuriyama H, Hotta K, Nakamura T, Shimomura I \& Matsuzawa Y. PPARgamma ligands increase expression and plasma concentrations of adiponectin, an adipose-derived protein. Diabetes $2001502094-2099$

3 Hotta K, Funahashi T, Arita Y, Takahashi M, Matsuda M, Okamoto Y, Iwahashi H, Kuriyama H, Ouchi N, Maeda K, Nishida M, Kihara S, Sakai N, Nakajima T, Hasegawa K, Muraguchi $M$, Ohmoto $Y$, Nakamura T, Yamashita $S$, Hanafusa T \& Matsuzawa Y. Plasma concentrations of a novel, adipose-specific protein, adiponectin, in type 2 diabetic patients. Arteriosclerosis, Thrombosis, and Vascular Biology 200020 1595-1599.

4 Zoccali C, Mallamaci F, Tripepi G, Benedetto FA, Cutrupi S, Parlongo S, Malatino LS, Bonanno G, Seminara G, Rapisarda F, Fatuzzo P, Buemi M, Nicocia G, Tanaka S, Ouchi N, Kihara S, Funahashi T \& Matsuzawa Y. Adiponectin, metabolic risk factors, and cardiovascular events among patients with end-stage renal disease. Journal of the American Society of Nephrology 200213 134-141.

5 Arita Y, Kihara S, Ouchi N, Takahashi M, Maeda K, Miyagawa J, Hotta K, Shimomura I, Nakamura T, Miyaoka K, Kuriyama H, Nishida M, Yamashita S, Okubo K, Matsubara K, Muraguchi M, Ohmoto Y, Funahashi T \& Matsuzawa Y. Paradoxical decrease of an adipose-specific protein, adiponectin, in obesity. Biochemical and Biophysical Research Communications 1999257 79-83.

6 Maeda N, Shimomura I, Kishida K, Nishizawa H, Matsuda M, Nagaretani H, Furuyama N, Kondo H, Takahashi M, Arita Y, Komuro R, Ouchi N, Kihara S, Tochino Y, Okutomi K, Horie M, Takeda S, Aoyama T, Funahashi T \& Matsuzawa Y. Diet-induced insulin resistance in mice lacking adiponectin/ACRP30. Nature Medicine 20028 731-737.

7 Kubota N, Terauchi Y, Yamauchi T, Kubota T, Moroi M, Matsui J, Eto K, Yamashita T, Kamon J, Satoh H, Yano W, Froguel P, Nagai R, Kimura S, Kadowaki T \& Noda T. Disruption of adiponectin causes insulin resistance and neointimal formation. Journal of Biological Chemistry $200227725863-25866$.

8 Fruebis J, Tsao TS, Javorschi S, Ebbets-Reed D, Erickson MR, Yen FT, Bihain BE \& Lodish HF. Proteolytic cleavage product of $30-k D a$ adipocyte complement-related protein increases fatty acid oxidation in muscle and causes weight loss in mice. PNAS 200198 2005-2010.

9 Okamoto Y, Kihara S, Ouchi N, Nishida M, Arita Y, Kumada M, Ohashi K, Sakai N. Shimomura I, Kobayashi H, Terasaka N, Inaba T, Funahashi T \& Matsuzawa Y. Adiponectin reduces atherosclerosis in apolipoprotein E-deficient mice. Circulation 2002 $1062767-2770$.

10 Yamauchi T, Kamon J, Waki H, Imai Y, Shimozawa N, Hioki K, Uchida S, Ito Y, Takakuwa K, Matsui J, Takata M, Eto K, Terauchi Y, Komeda K, Tsunoda M, Murakami K, Ohnishi Y, Naitoh T, Yamamura K, Ueyama Y, Froguel P, Kimura S, Nagai R \& Kadowaki T. Globular adiponectin protected ob/ob mice from diabetes and ApoE-deficient mice from atherosclerosis. Journal of Biological Chemistry 2003278 2461-2468.

11 Nakano Y, Tobe T, Choi-Miura NH, Mazda T \& Tomita M. Isolation and characterization of GBP28, a novel gelatin-binding protein purified from human plasma. Journal of Biochemistry $1996 \mathbf{1 2 0}$ $803-812$.

12 Pajvani UB, Du X, Combs TP, Berg AH, Rajala MW, Schulthess T, Engel J. Brownlee M \& Scherer PE. Structure-function studies of the adipocyte-secreted hormone Acrp30/adiponectin. Implications for metabolic regulation and bioactivity. Journal of Biological Chemistry 2003278 9073-9085.

13 Waki H, Yamauchi T, Kamon J, Ito Y, Uchida S, Kita S, Hara K, Hada Y, Vasseur F, Froguel P, Kimura S, Nagai R \& Kadowaki T. Impaired multimerization of human adiponectin mutants associated with diabetes. Molecular structure and multimer formation of adiponectin. Journal of Biological Chemistry $2003 \mathbf{2 7 8}$ $40352-40363$.

14 Weyer C, Funahashi T, Tanaka S, Hotta K, Matsuzawa Y, Pratley RE \& Tataranni PA. Hypoadiponectinemia in obesity and type 2 diabetes: close association with insulin resistance and hyperinsulinemia. Journal of Clinical Endocrinology and Metabolism 200186 1930-1935.

15 Peake PW, Kriketos AD, Denyer GS, Campbell LV \& Charlesworth JA. The postprandial response of adiponectin to a high-fat meal in normal and insulin-resistant subjects. International Journal of Obesity and Related Metabolic Disorders 2003 $27657-662$.

16 Kriketos AD, Sam W, Schubert T, Maclean E \& Campbell LV. Postprandial triglycerides in response to high fat: role of dietary carbohydrate. European Journal of Clinical Investigation 200333 383-389.

17 Greenstein JD, Peake PW \& Charlesworth JA. The kinetics and distribution of C9 and SC5b-9 in vivo: effects of complement activation. Clinical and Experimental Immunology 1995100 $40-46$.

18 Pajvani UB, Hawkins M, Combs TP, Rajala MW, Doebber T, Berger JP, Wagner JA, Wu M, Knopps A, Xiang AH, Utzschneider KM, Kahn SE, Olefsky JM, Buchanan TA \& Scherer PE. Complex distribution, not absolute amount of adiponectin, correlates with thiazolidinedione-mediated improvement in insulin sensitivity. Journal of Biological Chemistry 2004279 $12152-12162$.

19 Tsao TS, Murrey HE, Hug C, Lee DH \& Lodish HF. Oligomerization state-dependent activation of NF-kappa B signaling pathway by adipocyte complement-related protein of $30 \mathrm{kDa}$ (Acrp30). Journal of Biological Chemistry 2002277 29359-29362.

20 Tsao TS, Tomas E, Murrey HE, Hug C, Lee DH, Ruderman NB, Heuser JE \& Lodish HF. Role of disulfide bonds in Acrp30/adiponectin structure and signaling specificity: different oligomers activate different signal transduction pathways. Journal of Biological Chemistry $2003 \mathbf{2 7 8} 50810-50817$.

21 Peake PW, Charlesworth JA \& Pussell BA. Activation of rabbit C3: studies of the generation of cleavage products in vitro and of their metabolism in vivo. Complement and Inflammation 19918 $261-270$.

22 Schifferli JA, Pascual M, Steiger G, Schapira M, Ryser JE, Estreicher J \& Dash A. Fast liver catabolism of $\mathrm{Clq}$ in patients with paraproteinaemia and depletion of the classical pathway of complement. Clinical and Experimental Immunology 198769 $188-197$.

23 Melamed J, Alper CA, Cicardi M \& Rosen FS. The metabolism of C1 inhibitor and $\mathrm{Clq}$ in patients with acquired C1-inhibitor deficiency. Journal of Allergy and Clinical Immunology 198677 $322-326$.

24 English PJ, Coughlin SR, Hayden K, Malik IA \& Wilding JP. Plasma adiponectin increases postprandially in obese, but not in lean, subjects. Obesity Research 200311 839-844.

25 Blaak E. Gender differences in fat metabolism. Current Opinion in Clinical Nutrition and Metabolic Care 20014 499-502.

$26 \mathrm{Xu} \mathrm{A}$, Chan KW, Hoo RL, Wang Y, Tan KC, Zhang J, Chen B, Lam MC, Tse C, Cooper GJ \& Lam KS. Testosterone selectively reduces the high molecular weight form of adiponectin by inhibiting its secretion from adipocytes. Journal of Biological Chemistry $200528018073-18080$. 
27 Cnop M, Havel PJ, Utzschneider KM, Carr DB, Sinha MK, Boyko EJ, Retzlaff BM, Knopp RH, Brunzell JD \& Kahn SE. Relationship of adiponectin to body fat distribution, insulin sensitivity and plasma lipoproteins: evidence for independent roles of age and sex. Diabetologia 200346 459-469.

28 Kriketos AD, Greenfield JR, Peake PW, Furler SM, Denyer GS, Charlesworth JA \& Campbell LV. Inflammation, insulin resistance, and adiposity: a study of first-degree relatives of type 2 diabetic subjects. Diabetes Care 200427 2033-2040.

29 Yamauchi T, Kamon J, Ito Y, Tsuchida A, Yokomizo T, Kita S, Sugiyama T, Miyagishi M, Hara K, Tsunoda M, Murakami K, Ohteki T, Uchida S, Takekawa S, Waki H, Tsuno NH, Shibata Y, Terauchi Y, Froguel P, Tobe K, Koyasu S, Taira K, Kitamura T, Shimizu T, Nagai R \& Kadowaki T. Cloning of adiponectin receptors that mediate antidiabetic metabolic effects. Nature $2003 \mathbf{4 2 3}$ $762-769$

30 Wang Y, Xu A, Knight C, Xu LY \& Cooper GJ. Hydroxylation and glycosylation of the four conserved lysine residues in the collagenous domain of adiponectin. Potential role in the modulation of its insulin-sensitizing activity. Journal of Biological Chemistry 2002277 19521-19529.

31 Sato C, Yasukawa Z, Honda N, Matsuda T \& Kitajima K. Identification and adipocyte differentiation-dependent expression of the unique disialic acid residue in an adipose tissue-specific glycoprotein, adipo Q. Journal of Biological Chemistry 2001276 28849-28856.

32 Wang Y, Lam KS, Xu JY, Lu G, Xu LY, Cooper GJ \& Xu A. Adiponectin inhibits cell proliferation by interacting with several growth factors in an oligomerization dependent manner. Journal of Biological Chemistry $200528018341-18347$.

Received 9 February 2005

Accepted 1 June 2005 